\title{
CUEDC2 suppresses glioma tumorigenicity by inhibiting the activation of STAT3 and NF- $\kappa$ B signaling pathway
}

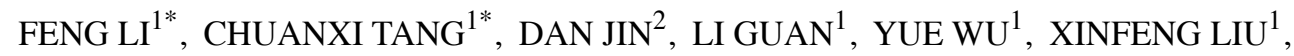 \\ XIUXIANG WU ${ }^{1}$, QING YUN WU ${ }^{3}$ and DIANSHUAI GAO ${ }^{1}$ \\ ${ }^{1}$ Department of Cell Biology and Neurobiology, Xuzhou Key Laboratory of Neurobiology, Xuzhou Medical University, \\ Xuzhou, Jiangsu 221004; ${ }^{2}$ School of Nursing, Xuzhou Medical University, Xuzhou, Jiangsu 221004; \\ ${ }^{3}$ Laboratory of Transplantation and Immunology, Xuzhou Medical University, \\ Xuzhou, Jiangsu 221002, P.R. China
}

Received February 7, 2017; Accepted March 27, 2017

DOI: 10.3892/ijo.2017.4009

\begin{abstract}
CUEDC2, a CUE domain containing 2 protein, plays critical roles in many biological processes, such as cell cycle, inflammation and tumorigenesis. However, whether CUEDC2 was involved in tumorigenesis of glioma and the possible mechanism remains to be elucidated. In the present study, our results implied that the expression of CUEDC2 was lower in the glioma tissue and glioma cell lines than that of normal tissue and asctrocyte cells. Downregulation of endogenous CUEDC2 in glioma U251 cell lines by RNAi promoted the tumor cells proliferation, migration, invasion and glioma neurosphere formation, while, overexpression of CUEDC2 showed the opposite effect. Further studies showed that overexpression of CUEDC2 suppressed the activation and nuclear translocation of phosphorylated-STAT3 (p-STAT3) but the level of p-STAT3 increased after interfering with the expression of CUEDC2. Moreover, CUEDC2 expression has an inhibitory effect on the activation of NF- $\kappa \mathrm{B}$. Thus, our studies suggested that the decreased expression of CUEDC2 in glioma led to the activation of transcription factor STAT3
\end{abstract}

Correspondence to: Professor Dianshuai Gao, Department of Neurobiology, Xuzhou Medical University, Tongshan Road 209, Xuzhou, Jiangsu 221002, P.R. China

E-mail: gds@xzhmu.edu.cn

*Contributed equally

Abbreviations: GBM, glioblastoma multiforme; p-STAT3, phosphorylated-STAT3; TMZ, temozolomide; GSC, glioma stem cells; NSC, neural stem cell; ER $\alpha$, estrogen receptor- $\alpha$; PR, progesterone receptor; IKK, IкB kinase; PP1, protein phosphatase; SOCS3, suppressors of cytokine signaling 3; WHO, World Health Organization; DAPI, 4'6-diamidino-2-phenylindole; PI, propidium iodide; CSCs, cancer stem-like cells

Key words: CUE domain containing 2, U251 glioma cell, glioma stem cell, STAT3, NF- $\kappa \mathrm{B}$ and $\mathrm{NF}-\kappa \mathrm{B}$ signaling pathway which may be related to the tumorigenicity in glioma.

\section{Introduction}

A central nervous system tumor is one of the most complicated human high-risk malignant tumors. Most primary brain tumors derived from glial cells or precursor cells are named glioma which can be subdivided into astrocytoma, oligodendroglioma, ependymoma and glioblastoma in light of the pathological type (1). According to the clinical malignant grade of tumors from the World Health Organization (WHO) (2), grades I and II are the least malignant phenotypes, such as oligodendroglioma and astrocytoma, grade III comprises the moderate malignant gliomas, such as anaplastic astrocytoma and anaplastic oligoastrocytoma, whereas grade IV (glioblastoma multiforme, GBM) is the most malignant type of gliomas (3). GBM is the most common and devastating primary brain tumor. Despite treatment with surgical section, chemotherapy with temozolomide (TMZ) and radiation, the median survival of patients is between 12 to 15 months (4) because of the high infiltrating capacity and near-universal tumor recurrence (5). Even with recent advances in cancer diagnostic methodology and treatment, the prognosis of GBM has not improved. Glioma stem cells (GSC) have been verified to be one of the major reasons for poor prognosis in GBM and other high grade primary brain tumors, making it nearly impossible to remove or kill all of these tumor cells by conventional therapies $(6,7)$. GSCs express normal neural stem cell (NSC) markers which are characteristic of self-renewal and multi-differentiation potential. GSCs can promote tumor proliferation, blood vessel growth and radiation and chemotherapy resistance, which all means GSCs play important roles in tumor recurrence and stemness maintenance of GBM $(8,9)$. Despite the progress in understanding of the molecular mechanisms involved in the genesis and progression of glioma, the prognosis and treatment of this tumor is still unsatisfactory (10).

CUEDC2 is a CUE domain containing protein, a small ubiquitin-binding motif with approximately 40 amino acid residues in many eukaryotic proteins. It has a dual role in monoubiquitin and polyubiquitin recognition, as well as in 
facilitating intramolecular monoubiquitination $(11,12)$. Recent studies have suggested that CUEDC2 played critical roles in many biological processes, such as cell cycle, inflammation and tumorigenesis (12).

As a multifunctional protein, the function of CUEDC2 in cancer is debated. Previous studies have indicated that CUEDC2 possesses both oncogenic and tumor-suppressive properties. It was reported that the CUEDC2 caused earlier activation of $\mathrm{APC} / \mathrm{cdc} 20$ to promote the metaphase-anaphase transition that led to chromosome missegregation and aneuploidy which might contribute to tumor development (13). Zhang et al (14) indicated that CUEDC2 inhibited APC/ cdh1 to promote the G1-S transition which might stimulate the proceeding of cell cycle in skin cancer where the expression of CUEDC2 was significantly elevated. Also, in breast cancer, CUEDC2 expression is elevated which promotes the degradation of estrogen receptor- $\alpha(E R \alpha)$ and progesterone receptor (PR) and further leads to the resistance to endocrine therapy by tamoxifen and early relapse (15-17). In ovarian serous carcinoma, CUEDC2 may be a promising biomarker and CUEDC2-positive expression was found to be associated with a shorter disease-free survival time (18).

However, other studies shown that the existence of CUEDC2 was beneficial to many kinds of normal tissues. High expression of CUEDC2 reduced colonic inflammatory reactions, decreased the expression of pro-inflammatory cytokines, significantly inhibited the activation of signaling pathways such as NF- $\mathrm{KB}$ and JAK1-STAT3 and prevented excessive proliferation of the inflammatory mucous epithelial cells which directly accelerated the occurrence of colorectal cancer (18). In lung adenocarcinoma cells, the promotion of proliferation by decreased CUEDC 2 was associated with activation of the PI3K/Akt pathway, which leads to a poor clinical outcome and a shorter survival time in patients (19). Moreover, CUEDC2 could inhibit the NF- $\mathrm{kB}$ signaling pathway to increase imatinib sensitivity in chronic myeloid leukemia (CML) cells (20). CUEDC2 could act as an adaptor protein to target I $\kappa$ B kinase (IKK) for dephosphorylation and inactivation by recruiting protein phosphatase (PP1), and thus, repressed the activation of $\mathrm{NF}-\mathrm{kB}$, signal pathway which played pivotal roles in inflammatory responses and tumorigenesis (15). Furthermore, CUEDC2 was found to regulate JAK1/STAT3 signaling pathway and to inhibit this pathway by increasing the stability of SOCS3 (suppressors of cytokine signaling 3) (21).

Although the roles of CUEDC2 in the development of many different cancers have been studied, its role in gliomas, especially in GBM is still unknown. However, this study showed that CUEDC2 was markedly downregulated in surgical specimens of GBM and glioma cell lines, especially in GSCs isolated from glioma cell line, the expression of CUEDC2 is extremely low. Overexpression of CUEDC2 inhibits proliferation, migration and invasion as well as arrests cell cycle at G1 phase of U251 glioma cells. In contrast, knockdown of CUEDC2 promoted cell proliferation, migration and invasion, as well as accumulation of cell cycle at G1 phase. Further studies showed that overexpression of CUEDC2 suppressed the activation and translocation of STAT3 and NF- $\mathrm{\kappa B}$ from the cell cytoplasm to the nucleus. Thus, our results suggested that the CUEDC2 played a tumor-suppressive role in glioma development.

\section{Materials and methods}

Preparation of glioma tissue samples. Glioma tissue samples were obtained during surgical removal of tumors from patients histopathologically diagnosed with different clinical pathology classification, and normal tissues were obtained from brain surgery from the Affiliated Hospital of Xuzhou Medical University. The histological characterization and clinicopathological staging of the samples were performed according to the World Health Organization (WHO) criteria which is the most widely accepted classification scheme for the diffuse gliomas.

Lentivirus package and constructions of stable cell lines. The 293T packaging cells were transfected with GV-CUEDC2/ GV-vector, Helper1.0, Helper2.0 using liposome-based transfection method and the packaged virus-containing supernatant was collected and used to infect U251 cells. Stable overexpression of CUEDC 2 and its control cell lines were obtained by flow cytometry sorting. Additionally, downregulation of CUEDC2 and its control cell lines were infected by lentivirus of GV-CUEDC2-RNAi and GV-RNAi-vector packaged virus. Then through puromycin lasting one week, stable cell lines were obtained. The cells stably overexpressing CUEDC2 or carrying the vector alone were named as 'U251-CUEDC2' cells, while those stably expressing the CUEDC2-specific RNAi were designated as 'RNAi-CUEDC2' or 'RNAi-vector' cells.

Identification of glioma stem cells isolated from U251. U251 cells were cultured normally, and then adding EGF $(20 \mathrm{ng} / \mathrm{ml})$, bFGF (20 ng/ml), LIF (10 ng/ml), B27 factors (x50) in serumfree conditions to culture U251 stem cells. GSCs were identified by labeling with rabbit anti-CD133 (polyclonal, 1:100; Proteintech Group, Inc., Rosemont, IL, USA) and mouse anti-Nestin (monoclonal, 1:100). GSCs were seeded in 48-well plates covered with polylysine and cultured for $48 \mathrm{~h}$. Then the old medium was discarded, washed 3 times with phosphatebuffered saline (PBS) and then cells were fixed for $30 \mathrm{~min}$ at room temperature in $4 \%$ formaldehyde. Fixed cells were permeabilized and blocked for $30 \mathrm{~min}$ at room temperature using $0.3 \%$ Triton X-100 and 5\% goat serum/PBS, and then wash 3 times with PBS and immunostained using CD133 and Nestin antibody overnight at $4^{\circ} \mathrm{C}$. The next day, washed 3 times with PBS, the secondary antibody (1:100; Vicmed Biotech Co., Ltd., Xuzhou, China), rhodamine (TRITC)-conjugated goat anti-mouse and Alexa Fluor488-conjugated AffiniPure goat anti-rabbit, were incubated for $2 \mathrm{~h}$ at room temperature in the dark. Nuclei were stained with 4'6-diamidino-2-phenylindole (DAPI). Fluorescence images were captured with fluorescent inverted microscope.

For glioma sphere formation assay, the U251 cells (5x104/well) were inoculated on 24 -well plate with serum-free DMEM F12 containing EGF, bFGF, LIF and B27 and cultured for 6 days, then images were taken.

Flow cytometric analysis of cell cycle. Cell cycle distribution was examined by flow cytometry according to the standard method. Cells were harvested by trypsinization and washed with cold PBS 3 times and then fixed with 70\% cold ethanol 
at $4^{\circ} \mathrm{C}$ overnight. Before staining, the cells were centrifuged in a cooled centrifuge and suspended in $100 \mu \mathrm{l}$ of RNase A (Nanjing KeyGen Biotech, Co., Ltd., Nanjing, China). After $30 \mathrm{~min}$ of $37^{\circ} \mathrm{C}$ incubation, incubation at $4^{\circ} \mathrm{C}$ followed for $30 \mathrm{~min}$ after adding $400 \mu \mathrm{l}$ propidium iodide (PI; Nanjing KeyGen Biotech). Samples were checked through FACScan cytometry (Becton-Dickinson, San Jose, CA, USA) and data were analyzed by FlowJo software (Tree Star, Inc., Ashland, OR, USA). Three independent experiments were carried out for each cell line.

Cell proliferation assay. Cell proliferation was detected via the Cell Counting Kit-8 assay (CCK-8; Dojindo Laboratories, Kumamoto, Japan). Cells were inoculated on a 96-well flatbottomed microplate, with a density of 4,000/100 $\mu \mathrm{l}$. After incubating $12 \mathrm{~h}$ until the cells grew to $50 \%$ confluence, $10 \mu \mathrm{l}$ CCK-8 dye was added to each well. Then incubated for 30, 60 and $90 \mathrm{~min}$ at $37^{\circ} \mathrm{C}$ and the absorbance at the wavelength of $450 \mathrm{~nm}$ was measured by a UVmax kinetic microplate reader (Molecular Devices, Wokingham, UK). The above results were regarded as the starting value ( 0 day), and then we checked the CCK- 8 results at the indicated time-points $(0,1,2,3$ and 4 days) and recorded the 30,60 and 90 min OD450 value.

In vitro migration and invasion assay. Cell migration was evaluated by scratch wound assay. Briefly, cells (10\% $/$ well) were plated in a 6-well plate and cultured for $48 \mathrm{~h}$ to yield a confluent monolayer. The culture solution was changed to serum-free Dulbecco's modified Eagle's medium (DMEM)/F12 at $6 \mathrm{~h}$ before wounding. Then wounded with a $10-\mu 1$ pipette tip. The remaining cells were washed twice with PBS and cultured with serum-free DMEM/F12. Photographs were taken at 0,24 and $48 \mathrm{~h}$. At the indicated times, migrating cells at the front of the wound were photographed and the percentage of the cleaned area at each time-point was compared with the area at time 0 . Each area was measured using Image-Pro Plus version 6.0 software.

Cell invasion was evaluated using a Transwell Matrigel invasion assay. Before the assay, $80 \mu \mathrm{l}$ of the diluted Matrigel was put into the upper chamber of 24-well Transwell chamber (Corning, Inc., Corning, NY, USA) and incubated at $37^{\circ} \mathrm{C}$ for gelling. The U251 cells were harvested and the cells suspended with serum-free DMEM/F12. Then inoculate cells into the upper chamber with a density of $2 \times 10^{4}, 4 \times 10^{4}$ and $8 \times 10^{4}$, respectively. Lower champer of the Transwell was filled with $600 \mu 1$ of $10 \%$ fetal bovine serum (FBS) culture medium, then incubated at $37^{\circ} \mathrm{C}$ for $20 \mathrm{~h}$ and removed the Transwell from 24 -well plates. Cells were fixed by $4 \%$ formaldehyde and stained by crystal violet staining solution.

Verification of quantitative real-time PCR. Total RNA of different cells groups was isolated using TRIzol reagent (Life technogies) according to the instruction manual. An ultraviolet spectrophotometer was used to measure the concentration and purity of total RNA. The first-strand cDNA was synthesized by Vic qRT Super kit (Vicmed Biotech) and qPCR using SYBR ${ }^{\circledR}$ qPCR Mix (Roche, Basel, Switzerland) and implemented on LightCycler ${ }^{\circledR} 480$ real-time fluorescence quantitative real-time PCR (Roche). qRT-PCR conditions were as follows: $30 \mathrm{sec}$ at $95^{\circ} \mathrm{C}, 30 \mathrm{sec}$ at $59^{\circ} \mathrm{C}$ and $1 \mathrm{~min}$ at $72^{\circ} \mathrm{C}$ for 40 cycles; $95^{\circ} \mathrm{C}$ for $2 \mathrm{~min}$, followed by 40 cycles of $95^{\circ} \mathrm{C}$ for $1.5 \mathrm{sec}$ and $60^{\circ} \mathrm{C}$ for $60 \mathrm{sec}$. GAPDH was used as reference gene and qRT-PCR was performed with three technical replicates for each sample on the same plate. Dissolution curve was used to analyze the characteristics of the PCR products. Relative expression levels of CUEDC2 gene were calculated by the $2^{-\Delta \Delta \mathrm{Ct}}$ formula.

Analysis of $p$-STAT3 and $N F-\kappa B$ expression and translocation. Coverglass was put into 24 -well plates then different groups of U251 cells were seeded into wells and cultured for 2 days to make sure of good growth. Then immunofluorescence staining experiment was done as described above. The cells were stained by labeling with rabbit anti-p-STAT3 (1:500; Bioworld Technology, Inc., St. Louis Park, MN, USA)

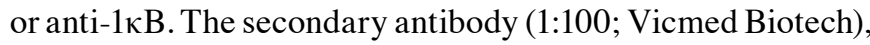
Alexa Flour 594-conjugated goat anti-rabbit was incubated for $2 \mathrm{~h}$ at room temperature in the dark. After staining with DAPI, glycerol was used to seal and fluorescence images were captured with Olympus BX43 microscope. The U251 cells overexpressed or knocked down of CUEDC 2 were seeded in the 6-well plates and then the protein was extracted for the western blot analysis. The antibodies used were: p-STAT3, STAT3, NF- $\kappa$ B and GAPDH (Cell Signaling Technology, Danvers, MA, USA).

Statistical analysis. All data were processed with the SPSS 16.0 (SPSS, Inc., Chicago, IL, USA). The measurement data are expressed as mean \pm standard deviation (SD). Independent sample t-test was used to determine significant differences in the mean values between the two groups. One-way analysis of variance (ANOVA) was used to compare the mean values of multiple samples. $\mathrm{P}<0.05$ was considered statistically significant for all tests.

\section{Results}

The expression of CUEDC2 in grade IV human glioma samples and cell lines is low compared with normal human brain tissue and asctrocyte cells, especially in GSC isolated from glioma cell line. Several independent microarray databases from Oncomine database was used to investigate the expression of CUEDC2 in gliomas. As shown in Fig. 1, the expression of CUEDC2 is low in glioblastoma compared to normal brain $(\mathrm{P}<0.05)$. The expression of CUEDC2 in GBM tumors was the lowest among various types of glioma.

Furthermore, the expression of CUEDC2 was detected in the clinical samples. Our results indicated that the mRNA and protein expression levels of CUEDC2 (Fig. 2A) were much lower in high grade glioma tissues than that of normal brain tissues. According the follow-up records from hospitals, most of the GBM cases (grade IV) which had low expression of CUEDC2 lead to shorter lifetime after surgical removal. Moreover, the expression of CUEDC2 in glioma cell lines was also analyzed and the results showed that there was lower expression of CUEDC2 in glioma cell lines than that of normal human asctrocyte (NHA) cells (Fig. 2B).

The expression of CUEDC2 in GSC isolated from U251 cells by the serum-free medium induced method was also 


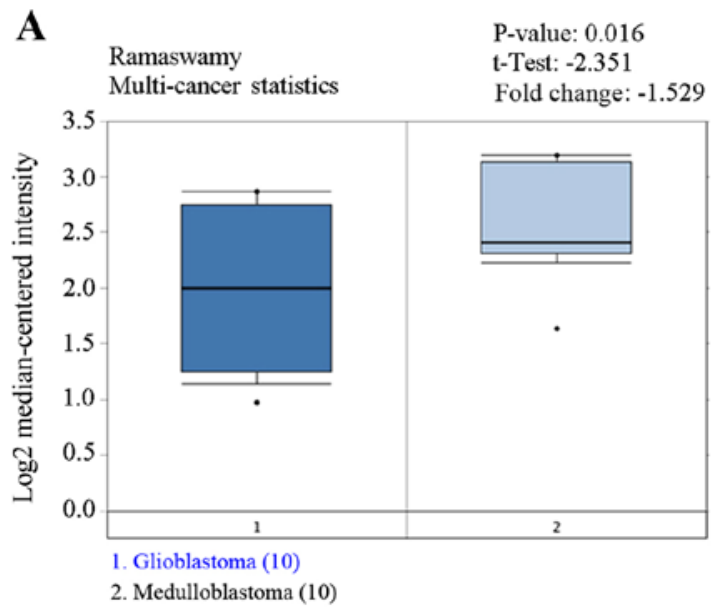

C
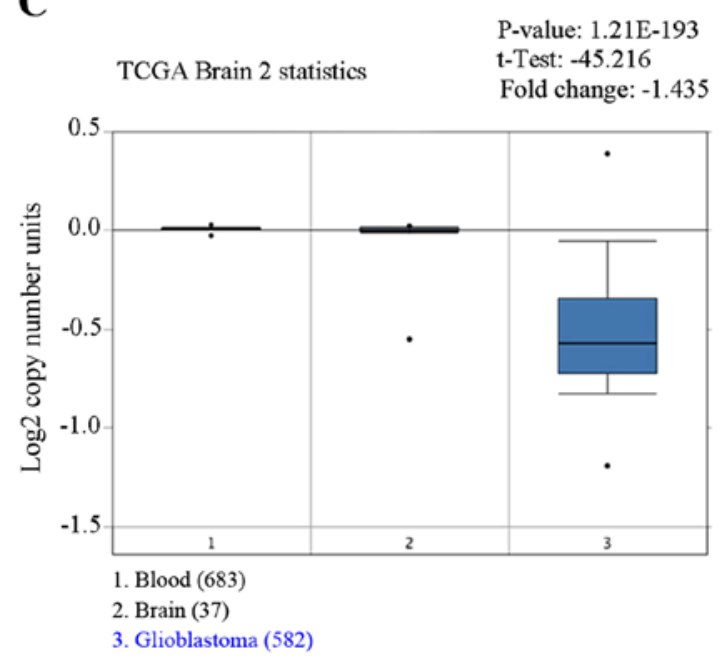

$\mathbf{E}$

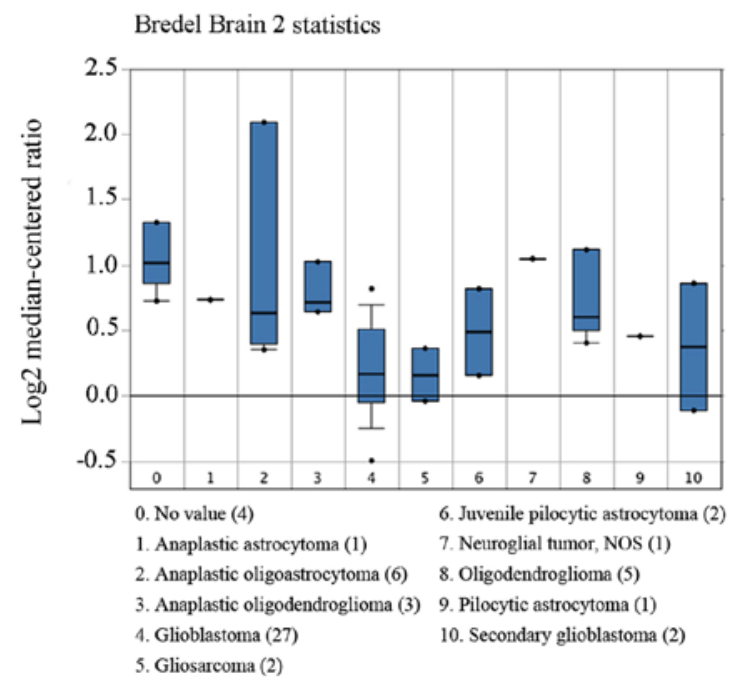

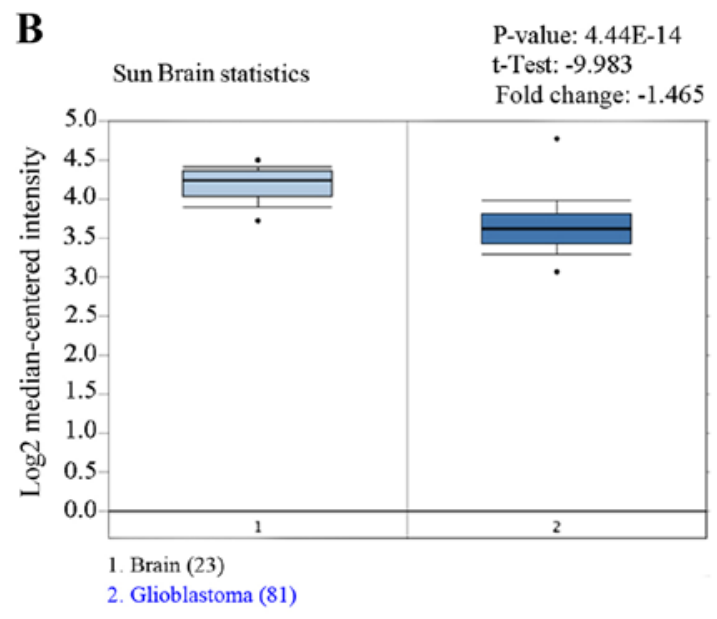

D

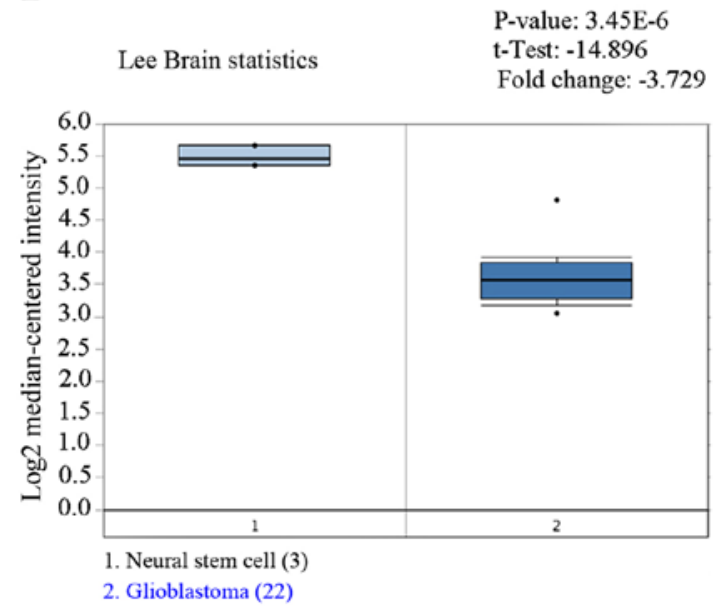

$\mathbf{F}$

TCGA Brain 2 statistics

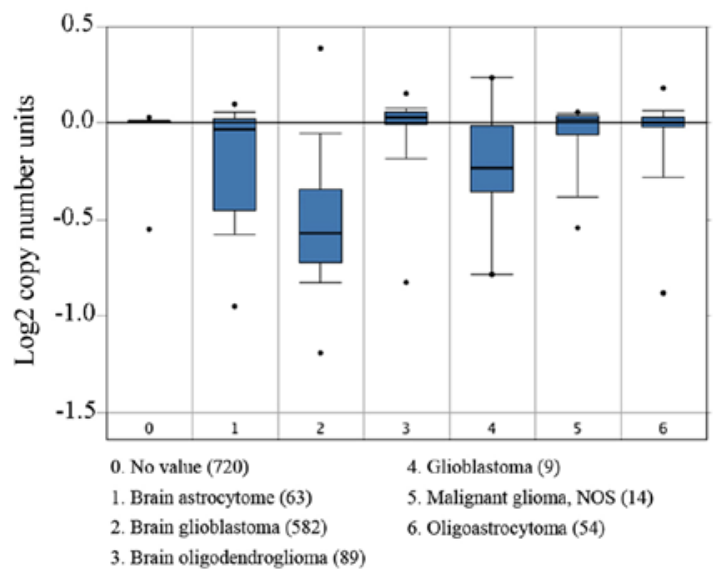

Figure 1. Microarray data extracted from Oncomine database. The expression of CUEDC2 gene obtained from (A) Ramaswamy Multi-cancer statistics, (B) Sun Brain statistics, (C) TCGA Brain 2 statistics, (D) Lee Brain statistics, (E) Bredel Brain 2 statistics and (F) TCGA Brain 2 statistics, various types of tumors respectively are shown as histograms. All statistics show that the expression of CUEDC2 was downregulated in glioblastoma.

determined. The isolated GSCs were identified using stem cells markers, CD133 and Nestin via immunofluorescence (Fig. 3A). Then, western blot analysis showed that the expression of CUEDC2 is extremely low (Fig. 3B) compared to
U251 cells. The results demonstrated that low expression of CUEDC2 might be related to the poor prognosis in high grade glioma, especially in GBMs and involved in the development of the GBM and the stemness of GSC. 
A
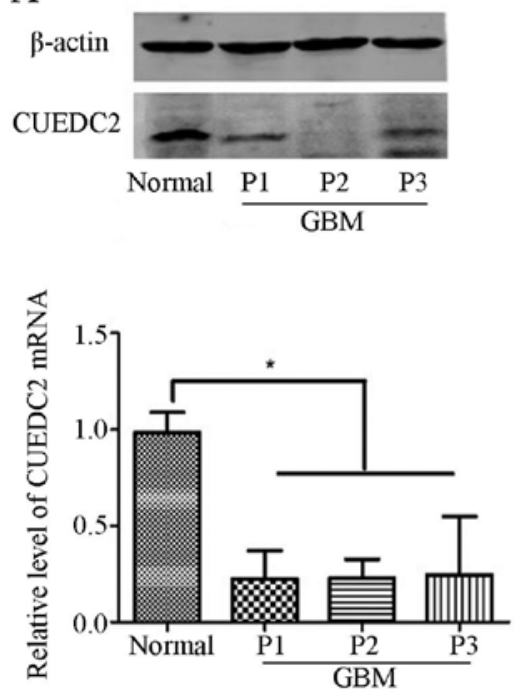

B
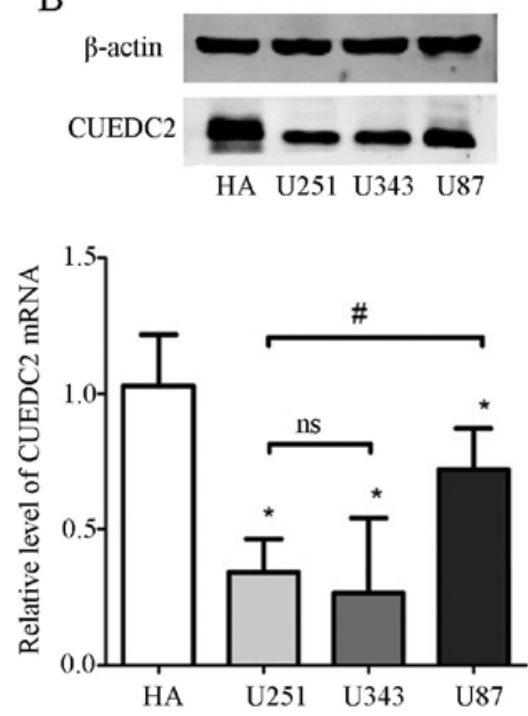

Figure 2. CUEDC2 is downregulated in higher grade glioma tissues. (A) The expression of CUEDC2 in the normal brain tissues, grade II and IV glioma patient tissues was detected by quantitative real-time PCR (qRT-PCR) and western blot analysis ( $\left.{ }^{*} \mathrm{P}<0.05\right)$. (B) The expression of CUEDC2 in the HA, U251, U343 and U87 cells was detected by quantitative real-time PCR (qRT-PCR) and western blot analysis (other groups compared with HA * $<0.05$; U251 compared with U87, ${ }^{\text {} P}<0.05$; U251 compared with U343; ns, no statistical significance).

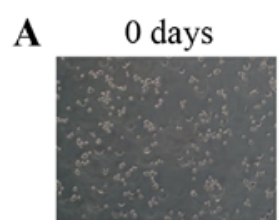

$\mathrm{CD} 133$

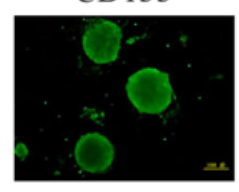

B

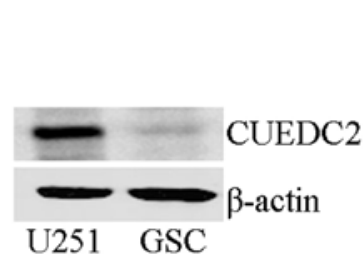

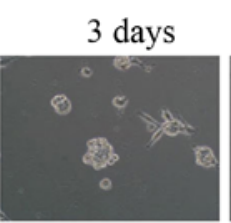

Nestin
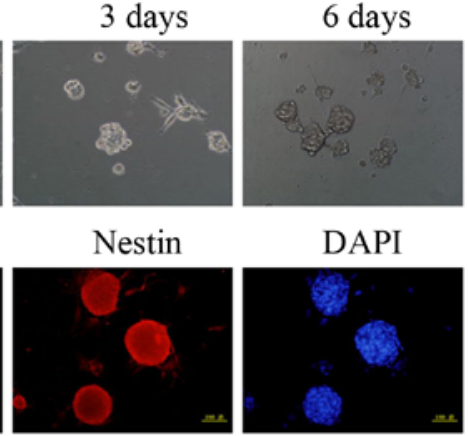

DAPI
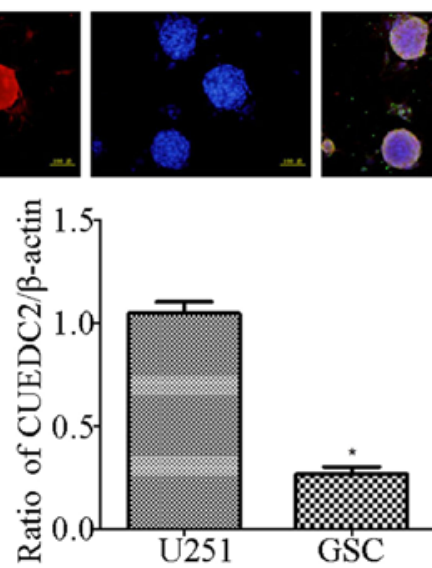

Figure 3. Induction and identification of stem cancer cells from U251, and the expression of CUEDC2 in the GSC were determined. (A) The induction process of glioma stem cancer cells by using EGF, bFGF, B27 and LIF factors. The pictures are shown in chronological sequence. Immunofluorescence was used to test the markers of stem cancer cells induced by 5 days. Green, CD133; red, Nestin; blue, DAPI. (B) The expression of CUEDC2 in the GSC was determined by the western blot analysis and qRT-PCR. ${ }^{*} \mathrm{P}<0.05$.

Overexpression of CUEDC2 inhibits the proliferation of U251 cells. In order to evaluate the roles of CUEDC2 in high grade glioma, the stable CUEDC2 overexpression (CUEDC2-OE) or CUEDC2 knockdown U251 cell line (CUEDC2-KD) was constructed by lentivirus, and screened by the puromycin and flow cytometry sorting. The western blot analysis and RT-PCR experiments verified the stable CUEDC2 overexpression or knockdown U251 cell line was obtained. The expression of CUEDC2 in protein and mRNA levels in CUEDC2-OE group was significantly higher than U251-vector control groups (Fig. 4A). Furthermore, the expression of CUEDC2 in CUEDC2-KD was decreased obviously (Fig. 4B). The RNAi sequence which has the best knockdown efficiency was chosen for the following experiments.

CCK-8 assay was applied toinvestigate theeffects ofCUEDC2 on proliferation. Compared with the control group, the growth rate of CUEDC2-OE U251 cells was evidently decreased on the 
A

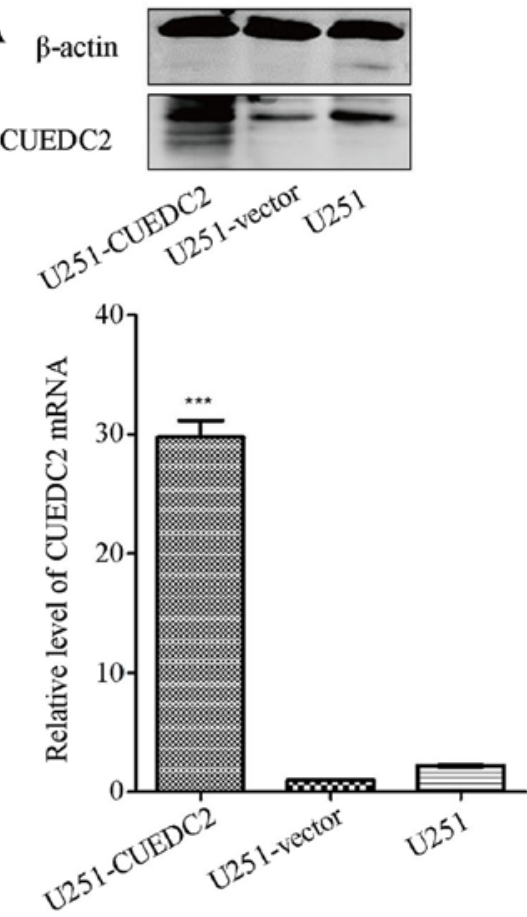

C

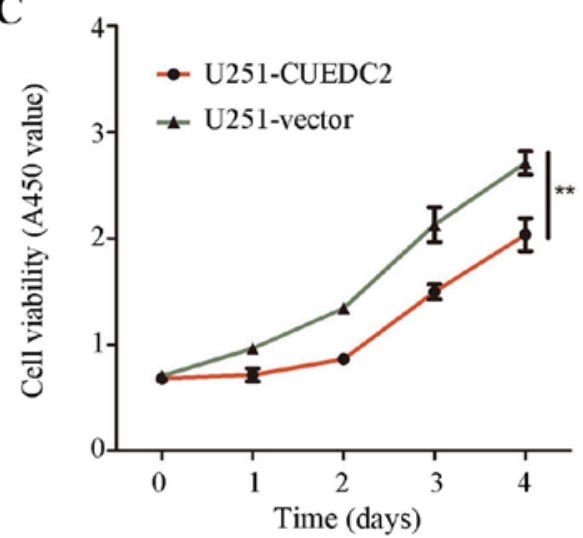

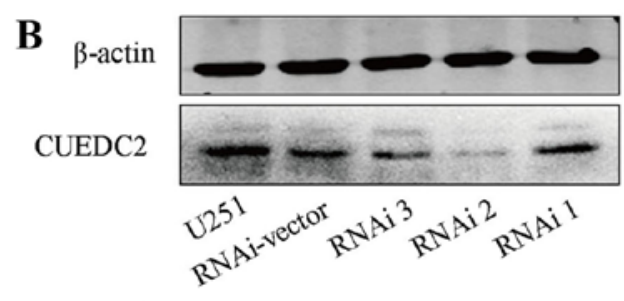

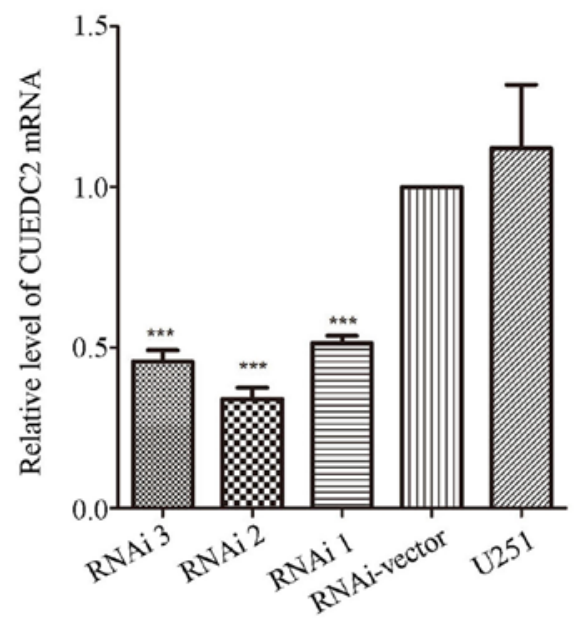

D

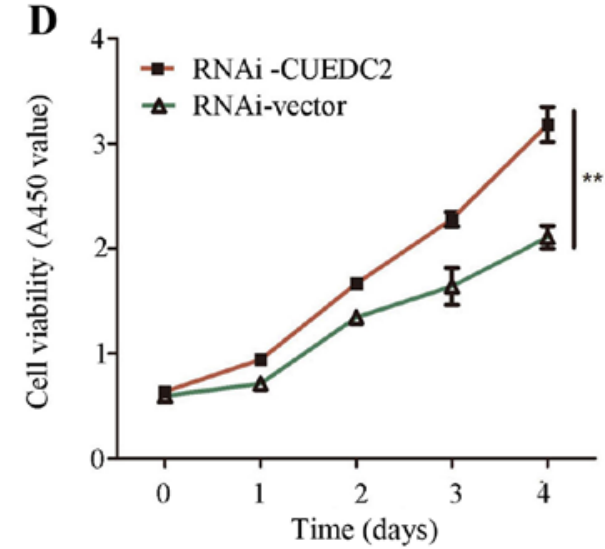

Figure 4. The effects of overexpression and knockdown expression of CUEDC2 on the U251 cell proliferation. (A and B) Overexpression (A) or knockdown (B) the expression of CUEDC2 by lentivirus, and the expression of CUEDC2 was assessed by western blot analysis and real-time RT-PCR. The effects of (C) overexpression and (D) knockdown of CUEDC2 on the U251 cell proliferation by Cell Counting Kit-8. ${ }^{*} \mathrm{P}<0.05$; ${ }^{* *} \mathrm{P}<0.01$.

fourth day (Fig. 4C). However, knockdown of the expression of CUEDC2 promoted proliferation of U251 cells (Fig. 4D). These results suggested that overexpression of CUEDC2 suppressed the proliferation of U251 cells. Downregulation of CUEDC2 promotes U251 cell G1-S and S-G2 phase transition, while overexpression of CUEDC2 arrests G1 phase. Cell proliferation is closely related to the cell cycle progression (22). To evaluate the effects of CUEDC2 on cell cycle, the cell cycle distribution of the stable cell lines overexpressed or knocked down of CUEDC2 was measured using flow cytometry. Our results showed that overexpression of CUEDC 2 caused cell cycle arrest at G1 phase compared to U251-vector cells (Fig. 5A and B), the population of U251-CUEDC2 cells in G1 phase was 44.47 \pm 2.09 compared to $39.78 \pm 3.55 \%$ of $\mathrm{U} 251$-vector group cells $(\mathrm{P}<0.05)$. Knockdown of the expression of CUEDC2 promoted the G1-S and $\mathrm{S}-\mathrm{G} 2$ phase transition. In particular, the percentage of $\mathrm{G} 2$ phase cells with U251-CUEDC2-KD group (21.5 $\pm 1.7 \%)$ was much higher than that of control group $(7.8 \pm 4.7 \%$ ) (Fig. $5 \mathrm{C}$ and D). Taken together, these results suggested that inhibiting the expression of CUEDC2 promoted DNA synthesis and the G1 to $\mathrm{S}$ phase cell cycle transition and lead to more cells entering into $\mathrm{G} 2 / \mathrm{M}$ phase.

Knockdown of the expression of CUEDC2 promotes U251 cell migration and invasion. The effect of CUEDC2 on glioma cell migration and invasion was detected. The scratch wound assay revealed that overexpression of CUEDC2 decreased the migration of U251-CUEDC2 cells compared with the U251 control group (Fig. 6A). Moreover, knockdown of the expression of CUEDC2 increased the U251 cell migration (Fig. 6B).

Subsequently, in vitro invasion experiment was explored by Transwell assay to analyze the effects of CUEDC2 on glioma cells. Our results demonstrated that overexpression of CUEDC2 
A

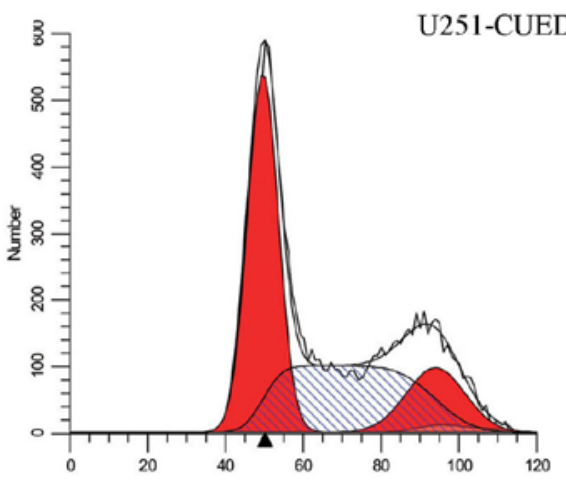

B

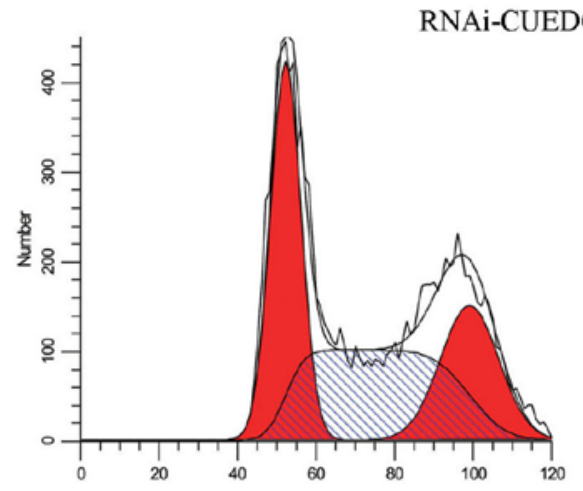

C

\begin{tabular}{cccc}
\hline \multicolumn{1}{c}{ Group } & \multicolumn{1}{c}{$\mathrm{G}_{\mathrm{o}} / \mathrm{G}_{1}(\%)$} & \multicolumn{1}{c}{$\mathrm{S}(\%)$} & $\mathrm{G}_{2} / \mathrm{M}(\%)$ \\
\hline U251-CUEDC2 & $44.47 \pm 2.09^{*}$ & $36.99 \pm 1.38 * *$ & $18.55 \pm 2.95$ \\
U251-vector & $39.78 \pm 3.55$ & $44.09 \pm 2.97$ & $16.09 \pm 6.25$ \\
\hline
\end{tabular}

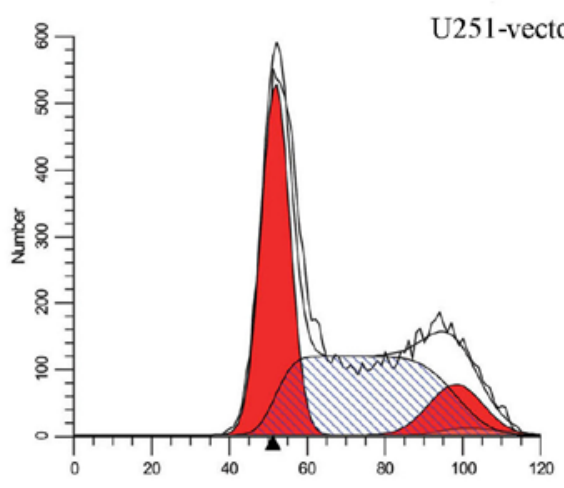

RNAi-vector

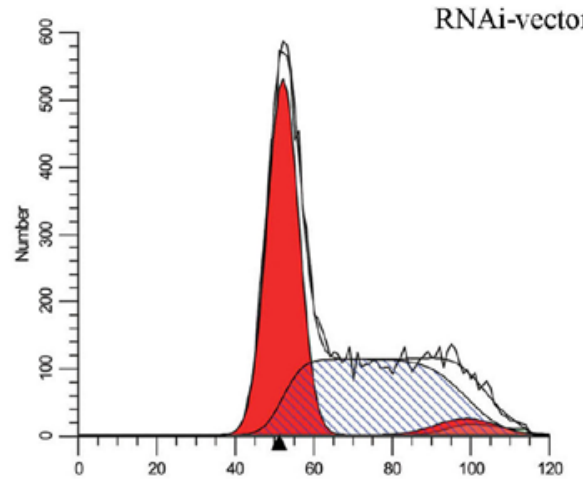

$\mathrm{D}$

\begin{tabular}{clcc}
\hline Group & $\mathrm{G}_{0} / \mathrm{G}_{1}(\%)$ & $\mathrm{S}(\%)$ & $\mathrm{G}_{2} / \mathrm{M}(\%)$ \\
\hline RNAi-CUEDC2 & $38.91 \pm 5.74^{*}$ & $39.50 \pm 4.78$ & $21.49 \pm 1.74^{* *}$ \\
RNAi-vector & $48.31 \pm 0.2$ & $43.89 \pm 4.91$ & $7.8 \pm 4.76$ \\
\hline
\end{tabular}

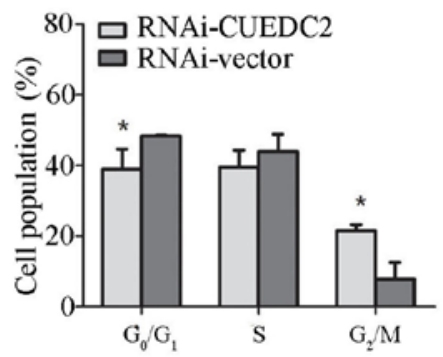

Figure 5. Effects of overexpression and knockdown expression of CUEDC2 on U251 cell cycle. (A and C) The data from flow cytometry of cell cycle distribution in U251-CUEDC2 and U251-vector groups. The statistical analysis from 3 tests. ("P<0.05). (B and D) Flow cytometric analysis of cell cycle distribution in LV-CUEDC2-RNAi and RNAi-vector groups. The statistical analysis from 3 tests (" $\mathrm{P}<0.05$ ). The percentage of cells in the G0/G1, S and G2/M phases was quantified and plotted. ${ }^{* *} \mathrm{P}<0.01$.

decreased the invasion of U251 cells. Different glioma cell density gradient: 2, 4 and 8 million cells separately showed the same trends (Fig. 7). All these results verified that CUEDC2 played an important role by suppressing migration and invasion.

Overexpression of CUEDC2 inhibits GSC neurosphere formatiom and knockdown of the expression of CUEDC2 promotes GSC sphere formation. The recurrence and incurability of glioma is related to the maintenance of GSC. In order to investigate the effects of CUEDC2 on the behavior of the GSC, the CUEDC2 stable overexpression or CUEDC2 knockdown GSC from CUEDC2-OE and CUEDC2-KD cells was obtained by serum-free medium culture. The glioma stem cells sphere formation experiment was carried out for about one week. The size of GSC from CUEDC2-OE is smaller, but larger GSC was obtained from CUEDC2-KD than that of control GSC from untransfected U251 cells (Fig. 8). These results indicated that CUEDC2 might inhibit the stemness of GSC and stem cell sphere formation.

Overexpression of CUEDC2 inhibits the activation of JAK1STAT3 and NF- $\kappa B$ pathways. The activation of JAK1-STAT3 pathway has been verified to play an important role in the progression of human gliomas. Activation of this pathway predicts poor prognosis of patients with gliomas (23). Therefore, whether CUEDC2 expression affects the JAK1STAT3 pathway in transgenic U251 cells was investigated. As shown in Fig. 9A, overexpression of CUEDC2 inhibited the 


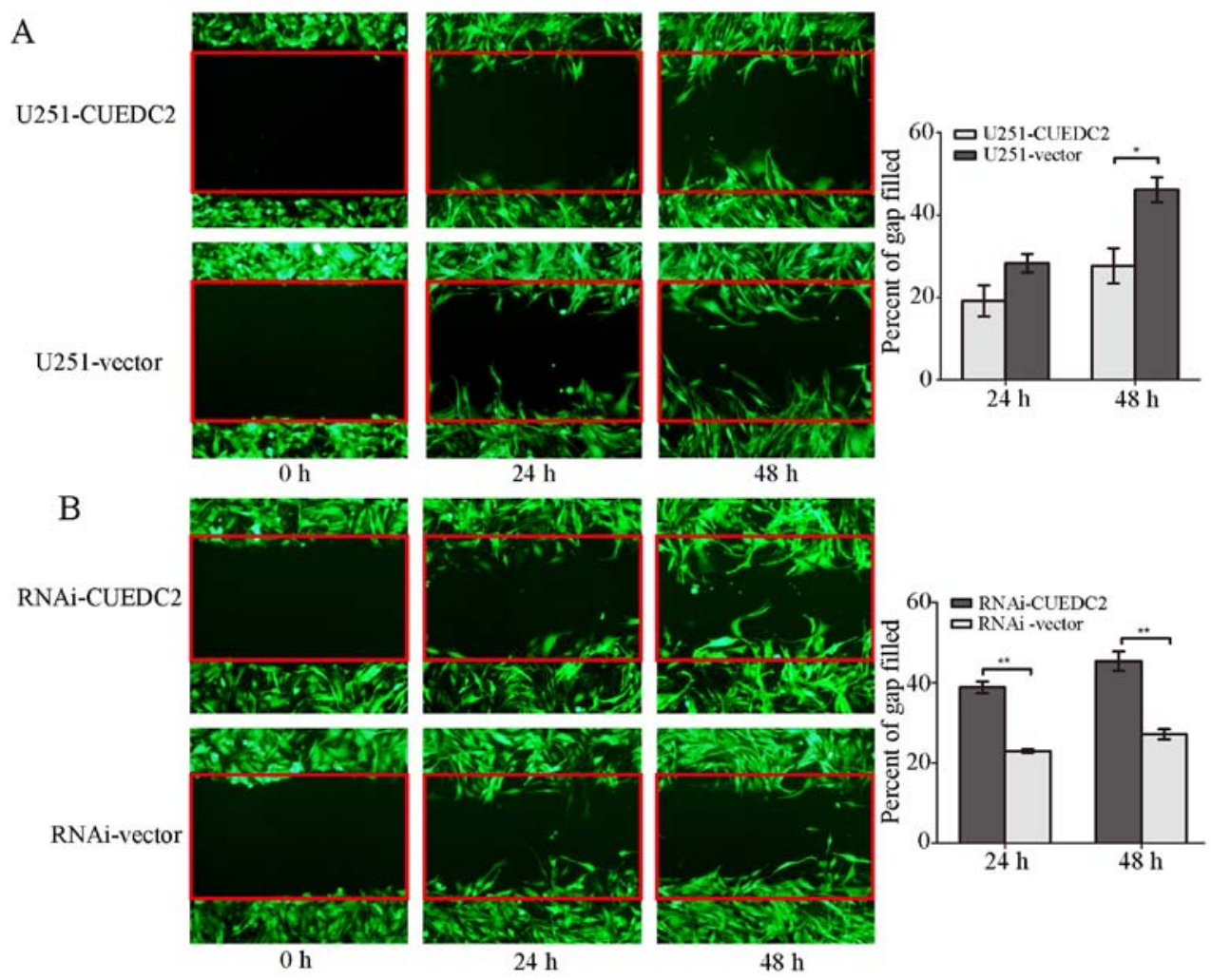

Figure 6. The effects of overexpression and knockdown of CUEDC2 on the U251 cell migration. (A) Overexpression of CUEDC2 by lentivirus, and the effect of the overexpression of CUEDC 2 on the U251 cell migration was assessed by wound healing method, each experiments with three replicates ( $\left.{ }^{* *} \mathrm{P}<0.01\right)$. (B) Knockdown of CUEDC 2 by lentivirus, and the effect of knockdown expression of CUEDC2 on the U251 cell migration was assessed by wound healing method, each experiments with three replicates. ${ }^{*} \mathrm{P}<0.05 ;{ }^{* *} \mathrm{P}<0.01$.
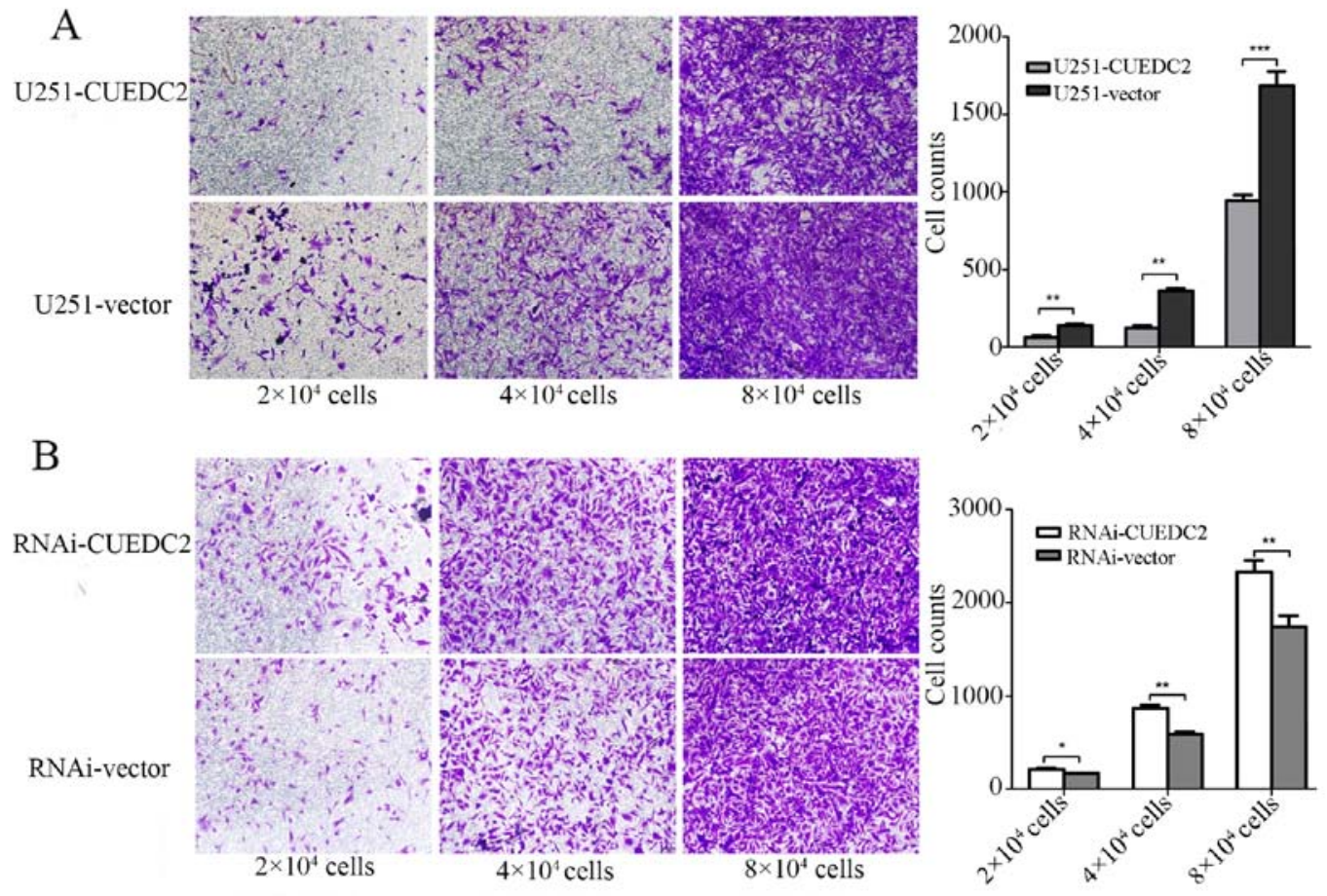

Figure 7. The effects of overexpression and knockdown expression of CUEDC2 on the U251 cell invasion. (A) Overexpression of CUEDC 2 by lentivirus, and the effect of the overexpression of CUEDC2 on the U251 cell invasion was assessed by cell invasion assay, each experiments with three replicates ("P $<0.05$, $\left.{ }^{* *} \mathrm{P}<0.01 ;{ }^{* * *} \mathrm{P}<0.001\right)$. Random pictures were recorded after transferring cells into Transwell $20 \mathrm{~h}$. We transferred cells were $\sim 2$ million, 4 million and 8 million into Transwells and compared with the same cell count groups, which confirmed the consistent conclusion. (B) Knockdown of the CUEDC2 by lentivirus, and the effect of knockdown expression of CUEDC 2 on the U251 cell invasion was assessed by cell invasion assay, each experiment with three replicates $\left({ }^{* *} \mathrm{P}<0.01\right)$. Random pictures were recorded after transferring cells into Transwell $20 \mathrm{~h}$. We transferred cells were $\sim 2$ million, 4 million and 8 million into Transwells and compared with the same cell count groups, which confirmed the consistent conclusion. 


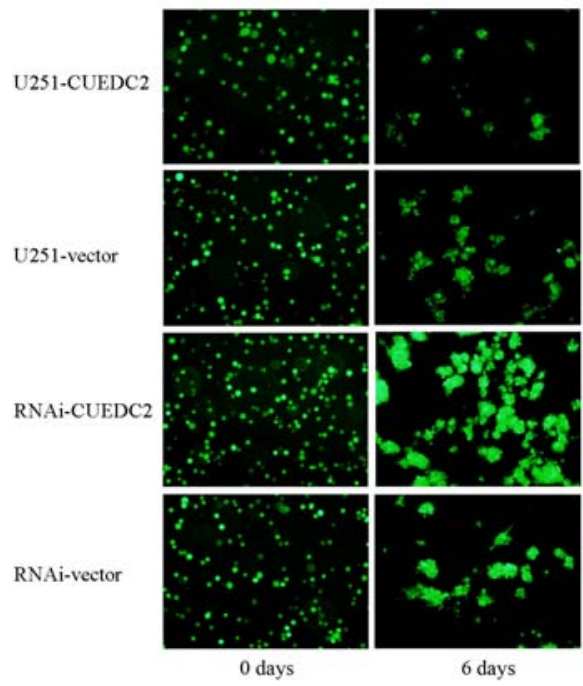

Figure 8. The effects of overexpression and the knockdown of CUEDC2 on the sphere formation of glioma stem cells. On the top panel, the effect of the overexpression of the CUEDC 2 on sphere formation of glioma stem cells from day 2, 4 to 6 . On the bottom panel, the effect of the knockdown expression of CUEDC 2 on the sphere formation of glioma stem cells from day 2, 4 to 6. (Scale bar, $50 \mu \mathrm{m}$ ). activation of JAK1-STAT3 signal pathway in U251 cells. The phosphorylation of STAT3 was increased in CUEDC2-RNAI cells compared to control U251 cells. The immunofluorescence experiments indicated that in the U251-CUEDC2 cells, STAT3 protein is mainly located in cytoplasm, while in the U251-CUEDC2-KD cells, an increase of STAT3 translocated to the nucleus was observed (Fig. 9B).

Furthermore, as is known, the existence of GSC is one of the origins of GBM tumorigenesis. The JAK1-STAT3 signaling pathway participated in the maintenance of self-renewal of GSC. Thus, the effect of CUEDC2 on this pathway in GSC was also detected. Overexpression of CUEDC2 in the GSC also decreased the activation of p-STAT3 and JAK1-STAT3 signal pathway (Fig. 9C).

$N F-\kappa B$ is an important transcription factor participating in inflammation and tumorigenesis. The activation of $\mathrm{NF}-\kappa \mathrm{B}$ was also analyzed. We found that the phosphorylation level of $1 \kappa \mathrm{B}$ is elevated after knockdown of CUEDC2 (Fig. 10) by western blot analysis. Moreover, the immunofluorescence assay indicated that overexpression of CUEDC2 inhibits the nuclear translocation of NF- $\mathrm{BB}$ and more NF- $\mathrm{B}$ was mainly concen-

A
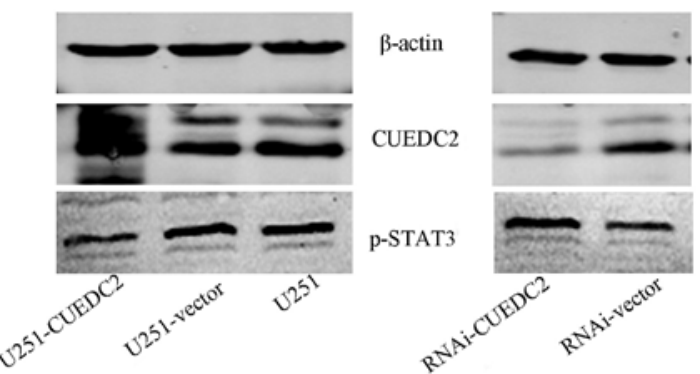

B

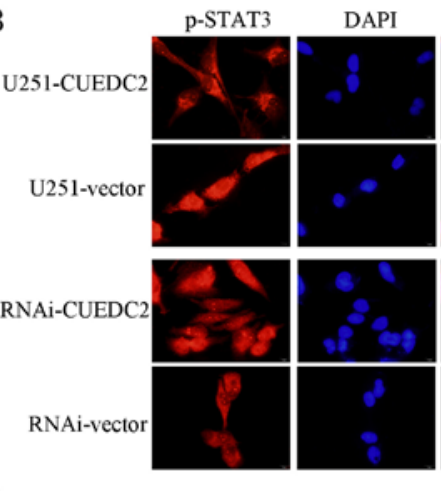

Merge
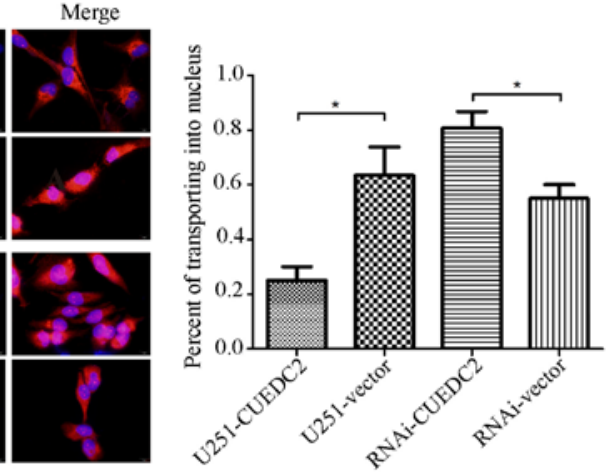

C

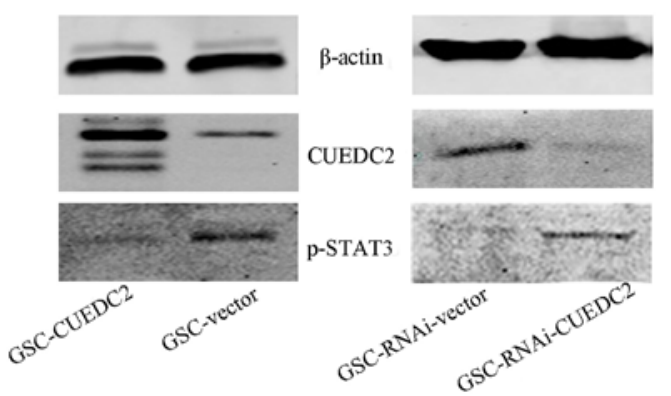

Figure 9. Effects of overexpression or knockdown of CUEDC2 on the phosphorylation of STAT3 (A and C) and the translocation of p-STAT3 from cytoplasm to nucleus (B) in the U251 cell (A) and GSC (C) was determined by western blot analysis and immunofluorescence. (A and C) Effects of the overexpression or knockdown of CUEDC2 on the phosphorylation of the STAT3 in the U251 cell (A) and GSC (C) was determined by the western blot analysis. Immunofluorescence images of p-STAT3 in U251-CUEDC2 group and control group. (B) Effects of the overexpression or knockdown of CUEDC2 on the translocation of p-STAT3 from cytoplasm to nuclear (C) in the U251 cells was determined by immunofluorescence (red, p-STAT3; blue, DAPI). Scale bars $20 \mu \mathrm{m}$ (left and middle) and $5 \mu \mathrm{m}$ (right). ${ }^{*} \mathrm{P}<0.05$. 

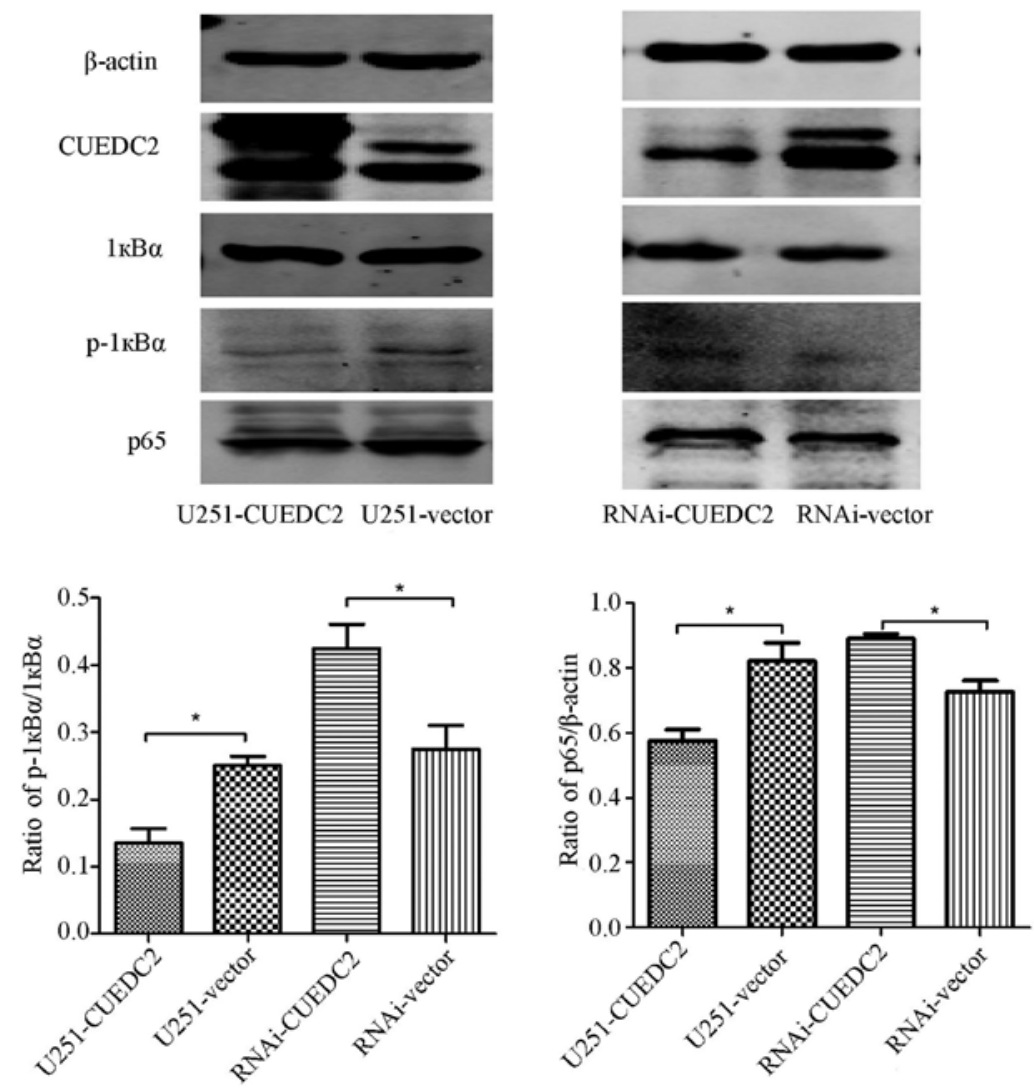

Figure 10. Effects of overexpression or knockdown of CUEDC2 on the activation of NF- $\mathrm{kB}$ signaling pathway was detected by western blot analysis. The western blot method was used to determine the overexpression or knockdown of CUEDC2 on endogenous IкB $\alpha$ phosphorylation and p65. "P<0.05.
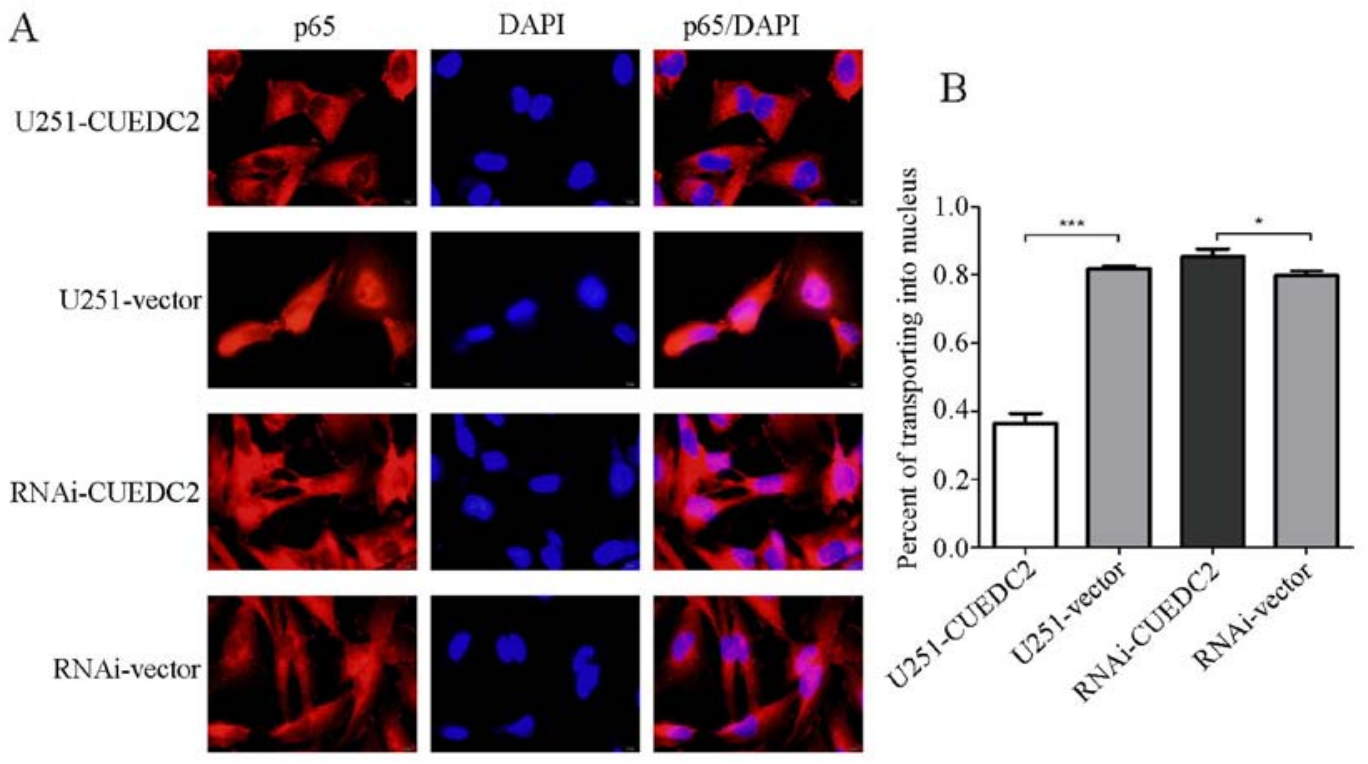

Figure 11. Effects of overexpression or knockdown of CUEDC2 on the p65 transportation was detected by the immunofluorescence. (A) Immunofluorescence images of p65 in different groups. (B) Statistical analysis of p65 transporting into the nucleus.

trated in the cytosol. More NF- $\mathrm{BB}$ flocked into the nucleus in the knockdown of CUEDC2 (Fig. 11). These results suggested that the downregulation of CUEDC2 in glioma may be related to the activation of JAK1-STAT3 and NF- $\mathrm{KB}$ pathway which plays an important role in tumorigenesis and malignancy.

\section{Discussion}

GSC has drawn research attention due to its roles in the high infiltrating capacity and near-universal malignant glioma recurrence (5). The major limitations of glioma treatment are 
the prevalence of recurrence after surgery, infiltration into surrounding tissues and intrinsic or acquired resistance to chemo- and radiotherapy. Intrinsic resistance to chemo- and radiotherapy is highly reminiscent of the recently emerging cancer stem-like cell theory, which holds that the cells with potent tumorigenic capacity are the same as those that contribute to tumor maintenance and recurrence. Cancer stem-like cells (CSCs), also called tumor-initiating cells, are a small population of tumor cells that self-renew like normal stem cells and are capable of inducing tumorigenesis. CSCs were first recognized in leukemia. The existence of CSCs was then identified in solid tumors such as brain, breast, colon, lung and other tissues. Notably, several independent reports have demonstrated the existence of brain tumor stem-like cells in different patient tissues. These cells are thought to be responsible for resistance to chemo- and radiotherapy, induction of tumor angiogenesis and tumorigenic capacity under hypoxic conditions. For this reason, CSCs are regarded as good potential therapeutic targets; however, critical molecular mechanisms that maintain the 'stemness' of CSCs are largely unknown. The molecular studies on GSCs such as geneexpression and differential protein analyzing bring out a nice prospect in classification of malignant gliomas and their molecular therapy $(24,25)$.

The Notch, Wnt and Sonic hedgehog, signaling pathways for development, are known to have important roles in maintaining stemness in the stem cell niche. These signaling pathway activation or inactivation may promote the development of glioma or maintain the stem cell stemness. Several markers, most of them previously described for neuroprogenitor cells, have been reported to identify GSC. Also, with the technical development, many genes, such as NANOG, OCT4, SOX2, EGFR, P53, SOCS1, STAT3 and JAK1 were proven to be critically involved in the regulation of selfrenewal and expansion of many different types of normal stem cells, including neural stem cells. Recently, CUEDC2 has drawn attention for its roles in different cancers such as breast, skin cancer, ovarian serous carcinoma and chronic myeloid leukemia. Furthermore, this gene was also proven to play important roles in the mataining of stemness of the breast cancer stem cells. Although the roles of this gene have been studied in the different cancers and stem cells, whether it played important roles in the development of the glioma and maintain the stemness in glioma stem cells is still unclear. In order to investigate the roles of CUEDC2 in the development of the glioma and the maintenance of the stemness in the glioma stem cells, the expression of CUEDC2 in the patients and the cell line was determined. The results from the Oncomine database showed that the expression of CUEDC2 in the GBMs from the patients was much lower than that of normal brains. Furthermore, this database also suggested that the expression of CUEDC2 in the patients had an inverse relationship with the glioma grade, and thus the expression of the CUEDC2 in the patients might be used as a prognostic indicator of gliomas or as a biomarker for the pathological level of glioma.

CUEDC2 is a CUE domain containing protein, located on chromosome 10 , roles of which in the development of cancer are still debated. It has a role in monoubiquitin and polyubiquitin recognition, as well as in facilitating intramolecular monoubiquitination $(11,26)$. The roles of the CUEDC2 have been studied in many different cancers, the functions of CUEDC2 seemed to have a dual function, either in tumor promotion or tumor suppression. Some research groups inferred the CUEDC2 as a tumor promoter; Gao et al (13) reported that CUEDC2 caused earlier activation of APC/Cdc20 to promote the metaphase-anaphase transition that led to chromosome missegregation and aneuploidy which might contribute to tumor development. Pan et al (16) further showed that CUEDC2 led to the resistance to endocrine therapy in breast cancer by promoting the degradation of estrogen receptor- $\alpha(\mathrm{ER} \alpha)$ and progesterone receptor (PR). Furthermore, Zhang et al (14) showed that CUEDC2 degradation was elevated for UV light-induced G1 arrest in skin cancer. Wang et al (18) also showed that CUEDC2 may be a promising biomarker and CUEDC2-positive expression was associated with a shorter disease-free survival time in ovarian serous carcinoma. Other research groups proved the CUEDC2 as a tumor suppressor, Sun et al (19) reported that the decreased CUEDC2 in lung adenocarcinoma cells led to a poor clinical outcome and a shorter survival time in patients. In order to determine whether the CUEDC2 played important roles in the development of glioma as the expression of CUEDC2 in the glioma grade indicated, the stable overexpression and downregulation of CUEDC2 cell lines, respectively, was constructed. Our results indicated that overexpression of CUEDC2 inhibits cell proliferation, migration and invasion. Then, we further analyzed the effect of CUEDC2 on cell cycle and GSCs sphere formation, which also suggested downregulation of CUEDC2 promoted G1-S and S-G2 phase transition and GSCs sphere formation. All in all, our results indicated that the CUEDC2 might be a tumor suppressor in the development of glioma which was consistence with Sun et al (19).

Although this study indicated that CUEDC2 played important roles in inhibiting the development of the glioma, the mechanism of how CUEDC2 affects development of the glioma was still unclear. As is known, hyper-activation of JAK1-STAT3 signaling pathway has close relationship to the development of certain types of human tumors. Previous studies reported that gliomas patients who possessed high-activation of JAK1 and STAT3 had lower overall survival rates than those with low JAK1 and STAT3 activation $(23,27)$. When the JAK1-STAT3 pathway is activated, STAT3 will be phosphorylated and phosphorylated-STAT3 (p-STAT3) forms dimers and translocates into the nucleus to regulate expression of genes by binding to elements of their promoters. It regulates many pathways which play important roles in tumorigenesis, including cell cycle progression, apoptosis, and tumor angiogenesis, metastasis, as well as tumor cell invasion of the immune system (28). The study by Wang et al (18) showed that CUEDC2 reduced colonic inflammatory reaction and inhibited the excessive proliferation of the inflammatory mucous epithelial cell through inhibiting the activation of $\mathrm{NF}-\kappa \mathrm{B}$ and STAT3. CUEDC2 has been reported to act as an adaptor protein to target $\mathrm{I} \kappa \mathrm{B}$ kinase (IKK) for dephosphorylation and inactivation by recruiting protein phosphatase (PP1), and have an inhibitory role in the activation of transcription factor $\mathrm{NF}-\kappa \mathrm{B}$ signaling pathway, which play pivotal roles in inflammatory responses 
and tumorigenesis (9). In the present study, the expression of IKB $\alpha$ was detected when CUEDC2 was overexpressed, our results implied that level of IKB $\alpha$ phosphorylation was decreased, when CUEDC2 is overexpressed in U251 cells. $\mathrm{IKB} \alpha$ is considered as an inhibitor of $\mathrm{NF}-\kappa \mathrm{B}$ signaling pathway, when phosphorylated, leading to the elimination or decreased NF- $\kappa \mathrm{B}$ signaling. The expression of $\mathrm{p} 65$ reduced and the amount of p65 transporting into the nucleus. All these results suggested that CUEDC2 inhibited the development of the glioma partially by affecting the NF- $\kappa \mathrm{B}$ signaling pathway. Accumulated evidence has shown that JAK1-STAT3 pathway activation plays an important role in tumorigenesis and progression $(29,30)$. Inhibiting the excessive activation of this pathway may become a therapeutic focus for treating GBM. Studies of Zhang et al (21) indicated that CUEDC2 and SOCS3 cooperate to negatively regulate JAK1-STAT3 pathway. In this study, our results indicated that overexpression of CUEDC2 inhibited the activation of the JAK1-STAT3 pathway and the STAT3 nucleus translocation. Thus, CUEDC2 may also inhibit the development of the glioma partially by affecting the JAK1-STAT3 signaling pathway. In total, our results implied that CUEDC2 affected the development of the glioma by influencing the activation of NF- $\mathrm{BB}$ and JAK1-STAT3 signaling pathways.

In the present study, the roles of CUEDC2 in the development of glioma was investigated, indicating overexpression of CUEDC2 inhibits cell proliferation, migration and invasion and GSC sphere formation. Our results also suggested that CUEDC2 affected the development of the glioma by influencing the activation of NF- $\kappa \mathrm{B}$ and JAK1STAT3 signaling pathway. Combined with the expression of CUEDC2 in the patient and the cell lines, all these result implied that CUEDC2 might be a tumor inhibitor in malignant glioblastoma. Thus, CUEDC2 may be considered as a potential diagnostic indicator and therapeutic targets for GBM treatment.

\section{Acknowledgements}

The present study was supported by grants from the National Natural Science Foundation of China (no. 81402073 and no. 81570136), the Natural Science Foundation of Jiangsu Province (BK20130218), the Program of the China Postdoctoral Science Foundation (2014M551663), the Foundation of Jiangsu Province Six Talents Peak (JY-061), the Key Project Supported by Jiangsu Province Universities (15KJA320005) and the Project Supported by Jiangsu Province Universities (15KJB310023).

\section{References}

1. Fuller GN and Scheithauer BW: The 2007 Revised World Health Organization (WHO) Classification of Tumours of the Central Nervous System: Newly codified entities. Brain Pathol 17: 304-307, 2007.

2. Louis DN, Ohgaki H, Wiestler OD, Cavenee WK, Burger PC, Jouvet A, Scheithauer BW and Kleihues P: The 2007 WHO classification of tumours of the central nervous system. Acta Neuropathol 114: 97-109, 2007.

3. Feng H, Liu KW, Guo P, Zhang P, Cheng T, McNiven MA, Johnson GR, Hu B and Cheng SY: Dynamin 2 mediates PDGFR $\alpha$-SHP-2-promoted glioblastoma growth and invasion. Oncogene 31: 2691-2702, 2012.
4. Helseth R, Helseth E, Johannesen TB, Langberg CW, Lote K, Rønning P, Scheie D, Vik A and Meling TR: Overall survival, prognostic factors, and repeated surgery in a consecutive series of 516 patients with glioblastoma multiforme. Acta Neurol Scand 122: 159-167, 2010.

5. Guryanova OA, Wu Q, Cheng L, Lathia JD, Huang Z, Yang J, MacSwords J, Eyler CE, McLendon RE, Heddleston JM, et al: Nonreceptor tyrosine kinase BMX maintains self-renewal and tumorigenic potential of glioblastoma stem cells by activating STAT3. Cancer Cell 19: 498-511, 2011.

6. Liebelt BD, Shingu T, Zhou X, Ren J, Shin SA and Hu J: Glioma stem cells: Signaling, microenvironment, and therapy. Stem Cells Int 2016: 7849890, 2016.

7. Bao S, Wu Q, McLendon RE, Hao Y, Shi Q, Hjelmeland AB, Dewhirst MW, Bigner DD and Rich JN: Glioma stem cells promote radioresistance by preferential activation of the DNA damage response. Nature 444: 756-760, 2006.

8. Bao S, Wu Q, Sathornsumetee S, Hao Y, Li Z, Hjelmeland AB, Shi Q, McLendon RE, Bigner DD and Rich JN: Stem cell-like glioma cells promote tumor angiogenesis through vascular endothelial growth factor. Cancer Res 66: 7843-7848, 2006.

9. Li Z, Bao S, Wu Q, Wang H, Eyler C, Sathornsumetee S, Shi Q, Cao Y, Lathia J, McLendon RE, et al: Hypoxia-inducible factors regulate tumorigenic capacity of glioma stem cells. Cancer Cell 15: 501-513, 2009.

10. Peñuelas S, Anido J, Prieto-Sánchez RM, Folch G, Barba I, Cuartas I, García-Dorado D, Poca MA, Sahuquillo J, Baselga J, et al: TGF-beta increases glioma-initiating cell self-renewal through the induction of LIF in human glioblastoma. Cancer Cell 15: 315-327, 2009.

11. Donaldson KM, Yin H, Gekakis N, Supek F and Joazeiro CA: Ubiquitin signals protein trafficking via interaction with a novel ubiquitin binding domain in the membrane fusion regulator, Vps9p. Curr Biol 13: 258-262, 2003.

12. Man J and Zhang X: CUEDC2: An emerging key player in inflammation and tumorigenesis. Protein Cell 2: 699-703, 2011.

13. Gao YF, Li T, Chang Y, Wang YB, Zhang WN, Li WH, He K, Mu R, Zhen C, Man JH, et al: Cdk1-phosphorylated CUEDC2 promotes spindle checkpoint inactivation and chromosomal instability. Nat Cell Biol 13: 924-933, 2011.

14. Zhang WN, Zhou J, Zhou T, Li AL, Wang N, Xu JJ, Chang Y, Man JH, Pan X, Li T, et al: Phosphorylation-triggered CUEDC2 degradation promotes UV-induced G1 arrest through APC/C $\mathrm{C}^{\mathrm{Cdh} 1}$ regulation. Proc Natl Acad Sci USA 110: 11017-11022, 2013.

15. Li HY, Liu H, Wang CH, Zhang JY, Man JH, Gao YF, Zhang PJ, Li WH, Zhao J, Pan X, et al: Deactivation of the kinase IKK by CUEDC2 through recruitment of the phosphatase PP1. Nat Immunol 9: 533-541, 2008.

16. Pan X, Zhou T, Tai YH, Wang C, Zhao J, Cao Y, Chen Y, Zhang PJ, Yu M, Zhen C, et al: Elevated expression of CUEDC2 protein confers endocrine resistance in breast cancer. Nat Med 17: 708-714, 2011.

17. Zhang PJ, Zhao J, Li HY, Man JH, He K, Zhou T, Pan X, Li AL, Gong WL, Jin BF, et al: CUE domain containing 2 regulates degradation of progesterone receptor by ubiquitin-proteasome. EMBO J 26: 1831-1842, 2007.

18. Wang S, Pu J, Li N, Li C, Li C, Yu L, Wang X, Fu S and Cui L: CUEDC2 protects against experimental colitis and suppresses excessive proliferation of intestinal mucosa. Dig Dis Sci 60: 3603-3609, 2015.

19. Sun L, Bai L, Lin G, Wang R, Liu Y, Cai J, Guo Y, Zhu Z and Xie C: CUEDC2 down-regulation is associated with tumor growth and poor prognosis in lung adenocarcinoma. Oncotarget 6: 20685-20696, 2015.

20. Zhang H, Chang G, Wang J, Lin Y, Ma L and Pang T: CUEDC2 sensitizes chronic myeloid leukemic cells to imatinib treatment. Leuk Res 37: 1583-1591, 2013h.

21. Zhang WN, Wang L, Wang Q, Luo X, Fang DF, Chen Y, Pan X, Man JH, Xia Q, Jin BF, et al: CUEDC2 (CUE domaincontaining 2) and SOCS3 (suppressors of cytokine signaling 3) cooperate to negatively regulate Janus kinase 1 /signal transducers and activators of transcription 3 signaling. J Biol Chem 287: 382-392, 2012.

22. Hanahan D and Weinberg RA: Hallmarks of cancer: The next generation. Cell 144: 646-674, 2011. 
23. Tu Y, Zhong Y, Fu J, Cao Y, Fu G, Tian X and Wang B: Activation of JAK/STAT signal pathway predicts poor prognosis of patients with gliomas. Med Oncol 28: 15-23, 2011.

24. Phillips HS, Kharbanda S, Chen R, Forrest WF, Soriano RH, Wu TD, Misra A, Nigro JM, Colman H, Soroceanu L, et al: Molecular subclasses of high-grade glioma predict prognosis, delineate a pattern of disease progression, and resemble stages in neurogenesis. Cancer Cell 9: 157-173, 2006.

25. Collins VP: Mechanisms of disease: Genetic predictors of response to treatment in brain tumors. Nat Clin Pract Oncol 4: 362-374, 2007.

26. Shih SC, Prag G, Francis SA, Sutanto MA, Hurley JH and Hicke L: A ubiquitin-binding motif required for intramolecular monoubiquitylation, the CUE domain. EMBO J 22: 1273-1281, 2003.
27. Carro MS, Lim WK, Alvarez MJ, Bollo RJ, Zhao X, Snyder EY, Sulman EP, Anne SL, Doetsch F, Colman H, et al: The transcriptional network for mesenchymal transformation of brain tumours. Nature 463: 318-325, 2010.

28. Osugi T, Oshima Y, Fujio Y, Funamoto M, Yamashita A, Negoro S, Kunisada K, Izumi M, Nakaoka Y, Hirota H, et al: Cardiac-specific activation of signal transducer and activator of transcription 3 promotes vascular formation in the heart. J Biol Chem 277: 6676-6681, 2002.

29. Yu H and Jove R: The STATs of cancer - new molecular targets come of age. Nat Rev Cancer 4: 97-105, 2004.

30. Lee H, Deng J, Kujawski M, Yang C, Liu Y, Herrmann A, Kortylewski M, Horne D, Somlo G, Forman S, et al: STAT3induced S1PR1 expression is crucial for persistent STAT3 activation in tumors. Nat Med 16: 1421-1428, 2010. 